\title{
BMJ Open Ethnic variations in five lower gastrointestinal diseases: Scottish Health and Ethnicity Linkage Study
}

\author{
Raj S Bhopal, ${ }^{1}$ Genevieve Cezard, ${ }^{1}$ Narinder Bansal, ${ }^{1,2}$ Hester J T Ward, ${ }^{1,3}$ \\ Neeraj Bhala, ${ }^{4,5}$ on behalf of the SHELS researchers
}

To cite: Bhopal RS, Cezard G, Bansal N, et al. Ethnic variations in five lower gastrointestinal diseases: Scottish Health and Ethnicity Linkage Study. BMJ Open 2014;4:e006120.

doi:10.1136/bmjopen-2014006120

- Prepublication history and additional material is available. To view please visit the journal (http://dx.doi.org/ 10.1136/bmjopen-2014006120).

Received 15 July 2014

Revised 15 August 2014

Accepted 21 August 2014

CrossMark

For numbered affiliations see end of article.

Correspondence to R S Bhopal; raj.bhopal@ed.ac.uk

\section{ABSTRACT}

Objectives: Our objective was to augment the limited evidence mainly from local, clinical studies of ethnic differences in gastrointestinal disorders. Our question was: are there ethnic variations in hospitalisation/death for lower gastrointestinal disorders in Scotland?

Setting: Scotland.

Population: This retrospective-cohort linked 4.65 (of 4.9) million people in the 2001 census of Scotland (providing data on ethnicity, country of birth and indicators of socioeconomic deprivation) to 9 years of National Health Service hospitalisation and death records.

Primary and secondary outcome measures and analysis: For appendicitis, we studied all ages; for irritable bowel syndrome, ulcerative colitis, Crohn's disease and diverticular disease, we included those $\geq 20$ years. Using Poisson regression (robust variance) we calculated, by ethnic group and sex, firsthospitalisation/death age-adjusted rates per 100000 person-years, and relative risks (RRs) with $95 \% \mathrm{Cls}$ multiplied by 100 , so the White Scottish reference population had an $\mathrm{RR}=100$.

Results: There were ethnic variations; for example, for irritable bowel syndrome, RRs ( $95 \% \mathrm{Cls}$ ) were comparatively high in Other White British women (128.4 (111.0 to 148.6)), and low in Pakistani women (75.1 (60.6 to 93.1)). For appendicitis, RRs were high in men in Other White British (145.2 (127.8 to 164.9)), and low in most non-White groups, for example, Pakistanis (73.8 (56.9 to 95.6)). For ulcerative colitis, RRs were high in Indian (169.8 (109.7 to 262.7)) and Pakistani (160.8 (104.2 to 248.2)) men. For Crohn's disease, the RR was high in Pakistani men (209.2 (149.6 to 292.6)). For diverticular disease, RRs were high in Irish men (176.0 (156.9 to 197.5)), and any Mixed background women (144.6 (107.4 to 194.8)), and low in most non-White groups, for example, Chinese men (47.1 (31.0 to 71.6) and women (46.0 (30.4 to 69.8)).

Conclusions: Appendicitis and diverticular disease were comparatively low in most non-White groups, while ulcerative colitis and Crohn's disease were mostly higher in South Asians. Describing and understanding such patterns may help clinical practice and research internationally.

\section{Strengths and limitations of this study}

- Ethnic variations can potentially improve causal understanding through hypothesis generation, but the literature is relatively sparse and mostly based on small clinical studies on a few ethnic groups.

- Ethnic variations were found on a national scale in Scotland using a retrospective cohort linkage study combining hospitalisation and mortality data, and studying up to 11 ethnic groups simultaneously.

- We have no data on the pattern of disease in the community or primary care setting.

- We have no data to explore the causal factors that lead to these ethnic variations.

More detailed studies are required and justified to test hypotheses based on our results.

\section{INTRODUCTION}

Gastrointestinal (GI) diseases such as diverticulitis, inflammatory bowel disease and appendicitis are common and disabling and their causes are incompletely understood. ${ }^{1}$ They are influenced by environmental factors, though the mechanisms of action are not clear cut. ${ }^{1-4}$ As ethnic or racial minority groups (henceforth, ethnic is used to include racial) are exposed to different environments, we would expect ethnic variations in these disorders. Ethnic variations within a country would partly reflect known international variations across countries. ${ }^{1}{ }^{2}{ }^{5-7}$ People born abroad should have disease rates that reflect both their country of birth or ancestral origin and of current residence, with convergence with increasing length of residence, as seen for other outcomes in migration and health studies. ${ }^{8}$ People from ethnic minority groups born in the country of study would be expected to have disease rates closer to those of the ethnic majority.

Ethnic variations in lower GI diseases have been demonstrated in a small scientific 
literature, both from the $\mathrm{UK}^{9-15}$ and internationally, including the USA. ${ }^{416-23}$ Some countries use country of birth as a proxy indicator of ethnicity. For example, mortality in England and Wales for diseases of the digestive system was high in Indian, Bangladeshi and Caribbean-born men compared to men born in England and Wales. ${ }^{24}$

These diseases seldom cause death when good healthcare is available, ${ }^{1}$ but they cannot be managed by primary care or outpatient services alone, and diagnosis, exacerbations or complications (eg, in ulcerative colitis) or the management of the initial problem (appendicitis) commonly requires specialist care and hospitalisation. ${ }^{1}$

We used the Scottish Health and Ethnicity Linkage Study (SHELS) ${ }^{25}$ to provide incidence of hospitalisation and/or death (either in the community or during hospitalisation). In Scotland, healthcare is funded from taxation and is free at the point of delivery to the resident population and hospitalisation/death data are collected centrally. The private healthcare sector comprises less than $1 \%$ of inpatient healthcare.

\section{METHODS}

The methods of SHELS have been published in detail, and this account draws on prior writing ${ }^{25}{ }^{26}$ while focusing on GI matters.

\section{Aim and hypotheses}

Our analysis was primarily descriptive to establish patterns of ethnic differences in the incidence of hospitalisation/death in lower GI diseases. Our prior hypothesis was that there were ethnic variations of $\geq 10 \%$ in pairwise comparison of each ethnic minority group to the White Scottish population in men and women separately. We further hypothesised that these variations would not be explained by available socioeconomic confounding factors. We were interested in the ethnic group variation in those born in the UK and those born abroad but did not have enough outcomes for stratified analysis. We used country of birth as a covariate to see whether it altered the risk ratio (RR). Our presumption was that being born in the UK would be associated with less difference between the White Scottish population and each comparison ethnic minority group in disease risk than being born abroad. If so, country-of-birth-adjusted risks would be expected to be closer to the White Scottish reference than those not so adjusted. If not, our data would not support convergence.

\section{Data on outcomes}

Our analysis examined all lower GI diseases where Information Services Division (ISD) published statistics showed that there were more than 1000 hospitalisations per year (a cut-off to ensure sufficient numbers for analysis and select outcomes for study). The previously linked hospital discharges and deaths, and out-of-hospital deaths, database held at the ISD provided data between 2001-2010 on irritable bowel disease (ICD 10 code K58), diverticular disease (K57.0, 57.2, 57.4, 57.8), appendicitis (K35-K38), ulcerative colitis (K51) and Crohn's disease (K50). The equivalent ICD 9 codes were used for hospitalisation before 1999. Diverticular disease data included both the large and small intestine. Diagnosis was as recorded by clinicians in hospital discharge and death records. The numerator was the first event for the above diagnoses. Up to six diagnoses on hospitalisation records and 11 in the mortality record were used. The data for the 10 years prior to the first hospitalisation identified between 2001and 2010 were checked. If no such admission was found, the event was considered incident, that is, a new case. A patient being admitted with one GI diagnosis (eg, Crohn's disease), but readmitted for another one (eg, ulcerative colitis), would be counted again. The outcomes include inpatient and day-case (no overnight stay in hospital) data.

Data on denominators, ethnic group, socioeconomic factors and country of birth

We used computerised matching of names, addresses and dates of birth to link the Census 2001 for Scotland to the Scottish Community Health Index (CHI), which is a register of patients using the National Health Service (NHS) in Scotland. Denominators were from this linked census 2001 data set. ${ }^{25-27}$ The census provided ethnic group (but not racial group), as reported by either individuals or the householder based on a question offering 14 categories, and other demographic data, including country of birth and socioeconomic variables. Eight socioeconomic indicators were assessed following our systematic approach. ${ }^{27}$

Ethnic group is legally required and was well completed (by $95.7 \%$ ) and, after imputation (4.3\%), available for $100 \%$ of those completing the census form. Generally, we followed the conventions on ethnic group labelling and categorisation, including capitalisation, of official Scottish Census reports. We minimised ethnic group aggregation, given the heterogeneity between populations that are commonly grouped, for example, Indians and Pakistanis as South Asians. ${ }^{8}$ Data cannot be reported for some groups because of the risk of disclosure of identity. We included the small number of Bangladeshis in the Other South Asian group. We combined Black, African and Caribbean populations into an African Origin group. We removed the any Other ethnic group as the population size and number of outcomes was small and we could not interpret data on such a diverse group.

\section{Data analysis}

To minimise the numbers of age/sex cells with no cases, which creates statistical instability, we restricted analysis to those $\geq 20$ years, excepting appendicitis which is common in young people. 
Person-years at risk were calculated using the linked population from 1 May 2001 to 30 April 2010, that is 9 years. The person-years calculation was adjusted by censoring follow-up at the date of death, date of diagnosis, and date of leaving the NHS in Scotland, if these occurred before April 2010. Data on emigration from the UK were not available. We constructed Poisson regression models with robust variance with age only (primary analysis) and then included the composite socioeconomic variable, the Scottish Index of Multiple Deprivation (SIMD), and country of birth. Age-adjusted rates for each ethnic group were derived by multiplying Poisson regression RRs adjusted for age and the White Scottish crude rates per 100000 PY. We calculated, by ethnic group and sex, first-hospitalisation/death age-adjusted relative risks (RRs) with $95 \%$ CIs multiplied by 100 , so the White Scottish reference population had an $\mathrm{RR}=100$. The analysis presented is the analysis planned and disclosed, so the reader can interpret the CIs in the light of the number of comparisons made.

Where tables or figures exclude a particular group, the numbers of outcomes were too small to be released by the National Records Scotland (NRS) Disclosure Committee.

Data were analysed using SAS V.9.3 (SAS Institute Inc, Cary, North Carolina, USA). The figures were created in SPSS.

The ethical and related issues have been reported, ${ }^{25} 28$ including an independent assessment by an ethicist. ${ }^{28}$ To comply with approvals, the data set only contained GI outcomes. The analysis was conducted on a stand-alone computer in a safe setting in NRS, by named researchers (NB, MS, GC-see Contributors), following a protocol. Outputs (including this paper) were screened by the NRS Disclosure Committee.

The authors had access to the study data and approved the final manuscript.

\section{RESULTS}

Characteristics of the study population and selection of socioeconomic indicators as confounding variables

The Web appendix table A1 shows the characteristics of the study population (all ages). There are large Other White British, White Irish and Other White minority populations but, excepting the Pakistani group, there were fewer than 10000 men and 10000 women in all non-White groups. The mean age of all non-White groups was lower than that of the White Scottish group (38 years), especially so for any Mixed background (21 years). Many non-White people were UK born, for example, $58 / \%$ of Pakistani males. On the three (of eight available) indicators of socioeconomic status shown, we see that the Other White British group had the highest socioeconomic status, with the picture being dependent on the indicator and sex for non-White ethnic groups.

The Web appendix table A2 shows associations between the GI disorders combined with eight socioeconomic factors. The Scottish Index of Multiple Deprivation (SIMD), a composite indicator of social and economic position based on the postcode (zipcode) of residence, was most consistently, positively associated with the outcome in all ethnic groups with $7 / 10$ associations having $95 \%$ CIs excluding zero in men, and $6 / 10$ excluding zero in women. This means that more socioeconomic deprivation is associated with more disease. In Other South Asian women, the association was marginally negative $(-0.7)$ with the $95 \%$ CI including zero. For all the other seven factors studied for at least one, but usually more, ethnic groups, the association was negative on several occasions. Furthermore, data on education and economic activity are only available for the age group 16-74 years. Following our methodology, ${ }^{27}$ we chose SIMD as the indicator that was most valid and complete across our ethnic groups.

\section{Focus of text describing the results}

All the comparisons below relate to the reference White Scottish population (stated or implied) and the text focuses on results where the age-adjusted 95\% CIs around RRs exclude 100. This approach, placing emphasis on the most precisely measured RRs, is appraised in the discussion.

\section{Combining deaths and hospitalisations and numbers of cases}

For all outcomes, the proportion of deaths was $1 \%$ or less, so mortality and hospital events were combined as in our pre-specified analysis plan. Over the 9 years, the numbers of cases at all ages were: diverticular disease (97 071), appendicitis (24997), irritable bowel syndrome (IBS) (15 793), Crohn's disease (7801) and ulcerative colitis (9414).

\section{Irritable bowel syndrome}

Table 1 and figure 1A show that for IBS in men and women, the RRs were higher in the Other White British group. The excess was attenuated but not abolished by adjustment by country of birth (table 1). Pakistani women had lower RRs with no sizeable change on adjustment.

\section{Appendicitis}

Table 2 and figure 1B show that males and females in Other White British, White Irish and Other White Groups had higher RRs for appendicitis. Adjustment for SIMD and country of birth made little difference (table 2). Pakistani males and Indian and Pakistani females had lower RRs, with little change on further adjustment. Any Mixed background females had a higher RR with no sizeable change on adjustment.

\section{Ulcerative colitis}

Table 3 and figure 1C show that the RRs for ulcerative colitis were higher in Indian men and Pakistani men and women. Adjustment for SIMD made little 
Table 1 Age adjusted rates per 100000 person years (PY) and relative risks (RR) for first irritable bowel syndrome hospitalisation or death for the population $\geq 20$ years by sex and ethnic group

\begin{tabular}{|c|c|c|c|c|c|c|c|}
\hline $\begin{array}{l}\text { Sex and ethnic } \\
\text { group }\end{array}$ & $\begin{array}{l}\text { Events } \\
\text { (N) }\end{array}$ & $\begin{array}{l}\text { PY at } \\
\text { risk }\end{array}$ & $\begin{array}{l}\text { Rates (per } \\
100,000 \text { PY) }\end{array}$ & $\begin{array}{l}\text { Age adjusted RR } \\
\text { and } 95 \% \mathrm{Cl}\end{array}$ & $\begin{array}{l}\text { Age and SIMD } \\
\text { adjusted RR and } \\
95 \% \mathrm{CI}\end{array}$ & $\begin{array}{l}\text { Age and COB } \\
\text { adjusted } \mathrm{RR} \\
\text { and } 95 \% \mathrm{Cl}\end{array}$ & $\begin{array}{l}\text { Age, SIMD } \\
\text { and COB adjusted } \\
\text { RR and } 95 \% \mathrm{CI}\end{array}$ \\
\hline \multicolumn{8}{|l|}{ Men } \\
\hline White Scottish & 3385 & 11918646 & 28.4 & 100.0 & 100.0 & 100.0 & 100.0 \\
\hline $\begin{array}{l}\text { Other White } \\
\text { British }\end{array}$ & 367 & 1070253 & 41.2 & 145.1 (117.8 to 178.7$)$ & $147.9(115.1$ to 189.9$)$ & $129.9(102.9$ to 163.9$)$ & $132.9(101.6$ to 173.9$)$ \\
\hline White Irish & 30 & 145226 & 25.1 & 88.4 (66.5 to 117.4$)$ & 86.8 (55.7 to 135.2$)$ & 78.5 (57.7 to 106.8$)$ & 77.4 (49.0 to 122.4 ) \\
\hline Other White & 42 & 176438 & 30.0 & $105.7(75.8$ to 147.4$)$ & 106.7 (75.3 to 151.3$)$ & 115.4 (82.1 to 162.2$)$ & 116.1 (79.7 to 169.2$)$ \\
\hline Indian & 11 & 35366 & 39.7 & 139.6 (89.1 to 218.8$)$ & 143.2 (82.9 to 247.5$)$ & 152.1 (89.3 to 259.0$)$ & 155.4 (83.8 to 288.4$)$ \\
\hline Pakistani & 18 & 64376 & 35.8 & 125.9 (90.6 to 175.0$)$ & 125.0 (83.9 to 186.2$)$ & 136.8 (93.0 to 201.4 ) & 135.6 (88.7 to 207.2 ) \\
\hline \multicolumn{8}{|l|}{ Women } \\
\hline White Scottish & 10680 & 13649520 & 78.2 & 100.0 & 100.0 & 100.0 & 100.0 \\
\hline $\begin{array}{l}\text { Other White } \\
\text { British }\end{array}$ & 922 & 1170149 & 100.5 & $128.4(111.0$ to 148.6$)$ & $132.6(115.7$ to 152.0$)$ & 127.5 (109.6 to 148.3$)$ & $133.1(115.2$ to 153.7$)$ \\
\hline White Irish & 117 & 165832 & 91.9 & 117.4 (93.6 to 147.2$)$ & 114.0 (94.0 to 138.2$)$ & 116.4 (91.7 to 147.8$)$ & 114.4 (94.0 to 139.3$)$ \\
\hline Other White & 102 & 213696 & 61.6 & 78.8 (58.6 to 105.9$)$ & 80.9 (61.3 to 106.8$)$ & 79.3 (61.2 to 102.9$)$ & 80.6 (62.9 to 103.4$)$ \\
\hline $\begin{array}{l}\text { Any Mixed } \\
\text { background }\end{array}$ & 19 & 21914 & 113.2 & 144.7 (95.1 to 220.2 ) & 141.6 (97.6 to 205.7 ) & 144.5 (98.0 to 213.0 ) & 141.8 (98.0 to 205.1$)$ \\
\hline Indian & 16 & 31626 & 64.3 & 82.2 (49.0 to 137.8$)$ & 85.8 (53.3 to 137.9$)$ & 82.6 (52.5 to 130.0$)$ & 85.5 (53.7 to 136.2$)$ \\
\hline Pakistani & 29 & 63449 & 58.8 & 75.1 (60.6 to 93.1$)$ & 73.7 (57.5 to 94.5$)$ & 75.5 (58.0 to 98.2$)$ & 73.5 (56.5 to 95.8$)$ \\
\hline
\end{tabular}



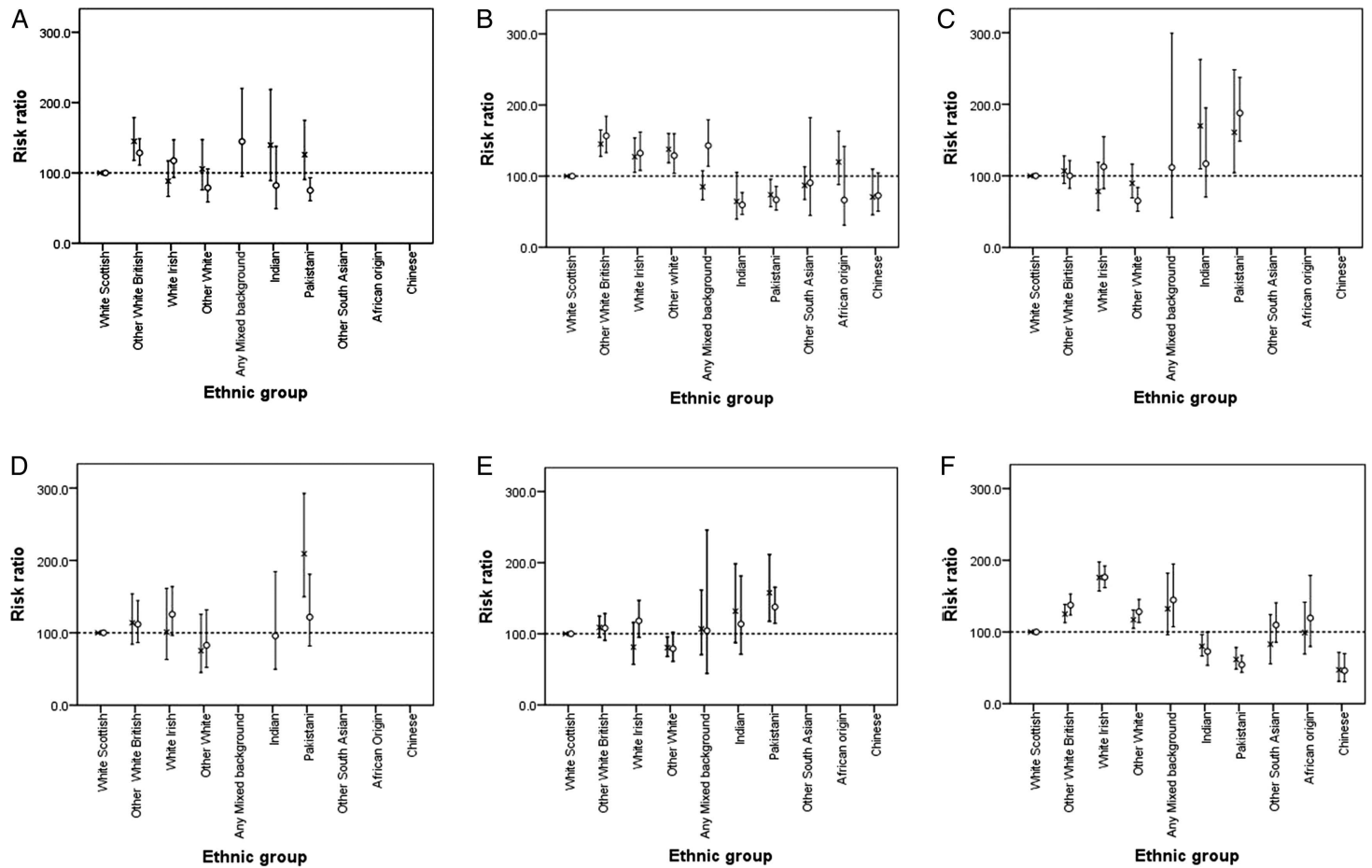

Figure 1 Age adjusted risk ratios (RR) for males (x) and females (o) by ethnic group. Bars show the $95 \% \mathrm{Cl}$ around the $\mathrm{RR}$, and the dotted line the RR of 100 in the White Scottish reference population. (A) Irritable bowel syndrome ( $\geq 20$ years);

(B) appendicitis (all ages); (C) ulcerative colitis ( $\geq 20$ years); (D) Crohn's disease ( $\geq 20$ years); (E) inflammatory bowel disease ( $\geq 20$ years); $(F)$ diverticular disease ( $\geq 20$ years).

difference, but adjustment for country of birth increased the RR further in Indian and Pakistani men (table 3). Other White women had lower RRs, with little effect of adjustment.

\section{Crohn's disease}

Table 4 and figure 1D show that the RR for Crohn's disease was more than doubled for Pakistani men. There was little change after adjustment for SIMD and an increase after adjustment for country of birth (table 4).

\section{Ulcerative colitis and Crohn's disease combined as inflammatory bowel disease}

The Web appendix table A3 and figure 1E show greater precision of estimates and more ethnic groups. However, the higher risk of ulcerative colitis in Indian men and the lower risk in Other White men are now lost, indicating a disadvantage of this approach. The main additional insight is that there were no differences of note in the any Mixed background.

\section{Diverticular disease}

Table 5 and figure $1 \mathrm{~F}$ show that Other White British, White Irish and Other White men and women had higher RRs of diverticular disease. Adjustment made little difference to the patterns (table 5). Indian, Pakistani and Chinese populations had lower RRs with little change after further adjustment. For the any Mixed background women, the RR was higher with little change on adjustment. The RRs were lower in Indian, Pakistani and Chinese men and women with little change on adjustment.

\section{DISCUSSION}

\section{Principal findings}

Ethnic variations in lower GI disorders varied by outcome. Variations were seen within White subgroups and White and non-White groups. Appendicitis and diverticular disease were mostly less common in Indian, Pakistani and Chinese (diverticular disease only) populations, while ulcerative colitis and Crohn's disease were more common in Indian and Pakistani men and women (ulcerative colitis only). The size of the differences was moderate, for example, with the maximal RR in Crohn's disease in Pakistani men $(\mathrm{RR}=209)$ and minimum in diverticular disease in Chinese women $(\mathrm{RR}=46)$. Together with the $95 \%$ CIs, the data suggest up to two to fourfold differences across ethnic groups. Ethnic variations were mostly not much altered by socioeconomic or country of birth adjustment. These data are relevant to health policy and planning and contribute to refining and developing causal hypotheses.

\section{Strengths and weaknesses of the study}

The general strengths and weaknesses of SHELS have been published. ${ }^{25}{ }^{26}$ The strengths include a population based, retrospective-cohort analysis; a self-reported indicator of ethnic group as well as country of birth; and 
Table 2 Age adjusted rates per 100000 person years (PY) and relative risks (RR) for first appendicitis hospitalisation or death for the whole population by sex and ethnic group

\begin{tabular}{|c|c|c|c|c|c|c|c|}
\hline $\begin{array}{l}\text { Sex and } \\
\text { ethnic group }\end{array}$ & $\begin{array}{l}\text { Events } \\
\text { (N) }\end{array}$ & PY at risk & $\begin{array}{l}\text { Rates (per } \\
100000 \text { PY) }\end{array}$ & $\begin{array}{l}\text { Age adjusted RR } \\
\text { and } 95 \% \mathrm{Cl}\end{array}$ & $\begin{array}{l}\text { Age and SIMD adjusted } \\
\text { RR and } 95 \% \mathrm{CI}\end{array}$ & $\begin{array}{l}\text { Age and COB adjusted } \\
\text { RR and } 95 \% \mathrm{Cl}\end{array}$ & $\begin{array}{l}\text { Age, SIMD and COB } \\
\text { adjusted RR and } 95 \% \mathrm{CI}\end{array}$ \\
\hline \multicolumn{8}{|l|}{ Males } \\
\hline $\begin{array}{l}\text { White } \\
\text { Scottish }\end{array}$ & 12567 & 16455586 & 76.4 & 100.0 & 100.0 & 100.0 & 100.0 \\
\hline $\begin{array}{l}\text { Other White } \\
\text { British }\end{array}$ & 852 & 1253049 & 110.9 & $145.2(127.8$ to 164.9$)$ & $145.5(128.8$ to 164.4$)$ & $149.2(131.2$ to 169.8$)$ & $149.6(131.3$ to 170.5$)$ \\
\hline White Irish & 89 & 161182 & 97.1 & $127.2(105.2$ to 153.7$)$ & $127.0(103.5$ to 156.0$)$ & $131.2(107.5$ to 160.2$)$ & 131.1 (106.0 to 162.2$)$ \\
\hline Other White & 172 & 224917 & 105.2 & $137.8(118.7$ to 160.0$)$ & $137.9(115.6$ to 164.6$)$ & $133.8(110.6$ to 161.9$)$ & $133.9(110.5$ to 162.3$)$ \\
\hline $\begin{array}{l}\text { Any Mixed } \\
\text { background }\end{array}$ & 31 & 43295 & 64.8 & $84.9(66.8$ to 107.8$)$ & $84.8(63.0$ to 114.2$)$ & $86.0(64.1$ to 115.4$)$ & 86.0 (62.3 to 118.6$)$ \\
\hline Indian & 21 & 51118 & 49.3 & 64.5 (39.5 to 105.3$)$ & 64.7 (42.0 to 99.6$)$ & 64.5 (39.3 to 105.9$)$ & 64.7 (42.5 to 98.4$)$ \\
\hline Pakistani & 59 & 111174 & 56.3 & 73.8 (56.9 to 95.6$)$ & 73.7 (56.9 to 95.3$)$ & 74.3 (57.8 to 95.6$)$ & 74.2 (57.2 to 96.2$)$ \\
\hline $\begin{array}{l}\text { Other South } \\
\text { Asian }\end{array}$ & 16 & 27567 & 66.5 & 87.1 (67.2 to 113.0$)$ & 87.0 (55.2 to 137.1$)$ & 85.9 (62.2 to 118.6$)$ & $85.8(53.2$ to 138.4$)$ \\
\hline African origin & 19 & 25143 & 91.6 & 119.9 (88.1 to 163.2$)$ & $119.6(77.1$ to 185.4$)$ & 117.7 (78.8 to 175.7$)$ & 117.3 (68.6 to 200.5$)$ \\
\hline Chinese & 25 & 53077 & 54.0 & 70.7 (45.5 to 110.0$)$ & 70.9 (49.7 to 101.1$)$ & 70.0 (49.1 to 99.6) & 70.1 (51.0 to 96.4 ) \\
\hline \multicolumn{8}{|l|}{ Females } \\
\hline $\begin{array}{l}\text { White } \\
\text { Scottish }\end{array}$ & 10046 & 18043991 & 55.7 & 100.0 & 100.0 & 100.0 & 100.0 \\
\hline $\begin{array}{l}\text { Other White } \\
\text { British }\end{array}$ & 739 & 1350187 & 87.2 & $156.6(133.0$ to 184.3$)$ & $156.9(134.2$ to 183.3$)$ & $160.4(136.2$ to 188.8$)$ & $160.7(137.0$ to 188.5$)$ \\
\hline White Irish & 75 & 180838 & 73.7 & $132.3(108.0$ to 162.1$)$ & $132.2(104.3$ to 167.5$)$ & $136.0(110.4$ to 167.4$)$ & 135.9 (106.8 to 172.9$)$ \\
\hline Other White & 133 & 261323 & 71.7 & $128.8(103.9$ to 159.7$)$ & $129.0(105.5$ to 157.7$)$ & $125.5(102.4$ to 153.7$)$ & $125.6(102.5$ to 154.0$)$ \\
\hline $\begin{array}{l}\text { Any Mixed } \\
\text { background }\end{array}$ & 37 & 46754 & 79.6 & 142.9 (114.0 to 179.2$)$ & $142.8(106.5$ to 191.5$)$ & 144.5 (116.6 to 179.2$)$ & $144.4(104.7$ to 199.3$)$ \\
\hline Indian & 13 & 46469 & 33.2 & 59.6 (46.1 to 76.9 ) & 59.7 (37.7 to 94.5$)$ & 59.6 (40.5 to 87.6$)$ & 59.8 (37.9 to 94.3$)$ \\
\hline Pakistani & 38 & 109301 & 37.2 & 66.8 (52.1 to 85.8$)$ & 66.7 (41.9 to 106.3$)$ & 67.3 (51.7 to 87.5$)$ & 67.2 (43.7 to 103.3$)$ \\
\hline $\begin{array}{l}\text { Other South } \\
\text { Asian }\end{array}$ & 10 & 22488 & 50.4 & 90.5 (44.9 to 182.4$)$ & 90.5 (47.1 to 173.6$)$ & 89.7 (47.2 to 170.6$)$ & 89.6 (47.9 to 167.5$)$ \\
\hline African origin & 7 & 22530 & 36.9 & 66.4 (31.0 to 142.0$)$ & $66.2(30.7$ to 142.4$)$ & 65.5 (33.5 to 127.9$)$ & 65.3 (32.6 to 130.7$)$ \\
\hline Chinese & 18 & 52897 & 40.5 & 72.7 (50.5 to 104.6$)$ & 72.9 (48.7 to 109.1$)$ & 71.8 (51.5 to 100.0$)$ & 71.9 (49.1 to 105.3$)$ \\
\hline
\end{tabular}

RRs are age, Scottish Index for Multiple Deprivation (SIMD) and country of birth (COB) adjusted, with 95\% Cls. 
Table 3 Age adjusted rates per 100000 person years (PY) and relative risks (RR) for first ulcerative colitis hospitalisation or death for the population $\geq 20$ years by sex and ethnic group

\begin{tabular}{|c|c|c|c|c|c|c|c|}
\hline $\begin{array}{l}\text { Sex and ethnic } \\
\text { group }\end{array}$ & $\begin{array}{l}\text { Events } \\
\text { (N) }\end{array}$ & PY at risk & $\begin{array}{l}\text { Rates (per } \\
100000 \mathrm{PY})\end{array}$ & $\begin{array}{l}\text { Age adjusted RR and } \\
95 \% \mathrm{Cl}\end{array}$ & $\begin{array}{l}\text { Age and SIMD adjusted } \\
\text { RR and } 95 \% \mathrm{Cl}\end{array}$ & $\begin{array}{l}\text { Age and COB adjusted RR } \\
\text { and } 95 \% \mathrm{Cl}\end{array}$ & $\begin{array}{l}\text { Age, SIMD and COB } \\
\text { adjusted } \\
\text { RR and } 95 \% \text { CI }\end{array}$ \\
\hline \multicolumn{8}{|l|}{ Men } \\
\hline $\begin{array}{l}\text { White } \\
\text { Scottish }\end{array}$ & 4140 & 11916407 & 34.7 & 100.0 & 100.0 & 100.0 & 100.0 \\
\hline $\begin{array}{l}\text { Other White } \\
\text { British }\end{array}$ & 320 & 1070499 & 37.1 & 106.9 (89.3 to 127.9$)$ & 106.6 (85.9 to 132.2$)$ & 94.3 (77.5 to 114.7$)$ & 93.9 (74.7 to 118.1$)$ \\
\hline White Irish & 32 & 145247 & 27.2 & 78.3 (51.6 to 118.9$)$ & 78.6 (55.3 to 111.7$)$ & 68.5 (44.9 to 104.5$)$ & 68.7 (47.9 to 98.5$)$ \\
\hline Other White & 41 & 176447 & 31.2 & 89.8 (69.2 to 116.5$)$ & 89.7 (64.9 to 123.8$)$ & 99.2 (70.6 to 139.5$)$ & 99.2 (69.9 to 140.7$)$ \\
\hline Indian & 15 & 35361 & 59.0 & 169.8 (109.7 to 262.7$)$ & 169.1 (99.1 to 288.6 ) & $187.8(112.1$ to 314.6$)$ & 187.2 (108.1 to 324.1$)$ \\
\hline Pakistani & 25 & 64355 & 55.9 & 160.8 (104.2 to 248.2$)$ & 160.9 (107.6 to 240.7$)$ & 176.9 (125.0 to 250.4$)$ & 177.1 (121.3 to 258.5$)$ \\
\hline \multicolumn{8}{|l|}{ Women } \\
\hline $\begin{array}{l}\text { White } \\
\text { Scottish }\end{array}$ & 4369 & 13678039 & 31.9 & 100.0 & 100.0 & 100.0 & 100.0 \\
\hline $\begin{array}{l}\text { Other White } \\
\text { British }\end{array}$ & 318 & 1172839 & 32.0 & $100.1(82.5$ to 121.5$)$ & 100.6 (82.8 to 122.2$)$ & 95.8 (75.7 to 121.2$)$ & 96.5 (78.4 to 118.7$)$ \\
\hline White Irish & 53 & 166142 & 36.0 & 112.7 (82.2 to 154.6$)$ & 112.1 (84.3 to 149.0$)$ & 107.5 (76.2 to 151.5$)$ & 107.1 (79.8 to 143.6$)$ \\
\hline Other White & 36 & 213979 & 20.8 & 65.1 (50.5 to 84.0$)$ & $65.4(49.2$ to 86.8$)$ & 67.9 (49.5 to 93.2$)$ & 68.0 (49.9 to 92.8$)$ \\
\hline $\begin{array}{l}\text { Any Mixed } \\
\text { background }\end{array}$ & 6 & 21954 & 35.7 & 111.7 (41.7 to 299.0$)$ & 111.3 (53.6 to 231.3 ) & 110.6 (41.1 to 297.2$)$ & 110.2 (58.0 to 209.5$)$ \\
\hline Indian & 9 & 31650 & 37.4 & 117.0 (70.3 to 195.0$)$ & 117.8 (62.2 to 223.4$)$ & 120.9 (64.4 to 227.0$)$ & 121.6 (62.0 to 238.3 ) \\
\hline Pakistani & 28 & 63451 & 60.0 & $187.8(148.3$ to 237.7$)$ & 187.3 (137.1 to 255.9$)$ & 193.4 (142.7 to 262.0$)$ & 192.7 (139.4 to 266.4$)$ \\
\hline
\end{tabular}

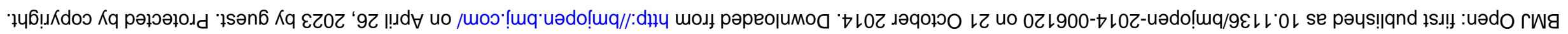




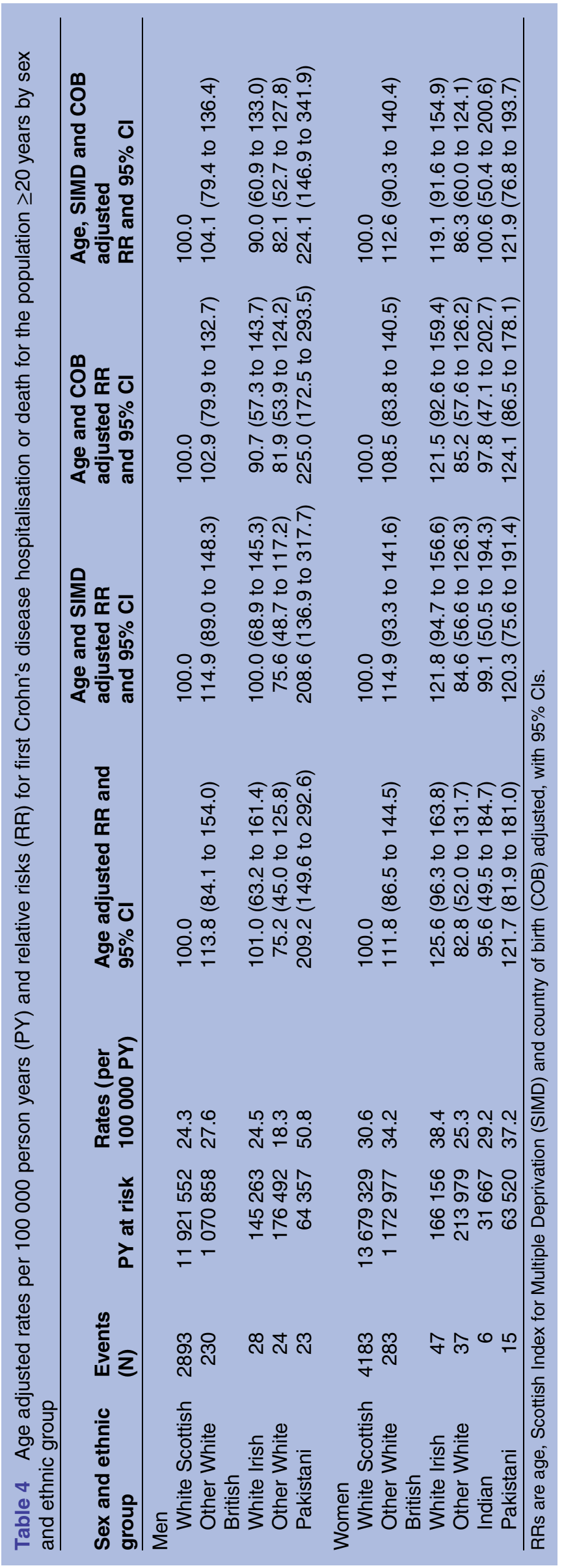

access to a range of socioeconomic factors. The weaknesses include incomplete linkage $(95 \%$ overall with $85 \%$ or more for every ethnic group); the use of routinely collected data; and unavailability of risk factor data.

In this analysis, the strength is the provision of new cohort data on five GI outcomes by ethnic group using all diagnostic data in hospital and death records. It has shown, for the first time, that there are variations among White groups, and it has confirmed important differences in comparisons of White and non-White ethnic groups. The Mixed Ethnic group is rarely studied, but this analysis has provided information, albeit on a small population. Data on Chinese populations living abroad are also rare and we have added to a sparse prior literature.

Even over 9 years, the number of outcomes for some ethnic minority groups was small; hence, $95 \%$ CIs were sometimes wide. There is a risk of type 2 statistical error. There may be differences that we did not observe or did not highlight because we focused on results where the 95\% CIs excluded the reference value. This approach reduces the risk of reaching conclusions that result from type I statistical error. It would be perfectly appropriate given the principles underlying CIs, however, to also examine the other results. Whatever approach is taken, the interpretation requires knowledge of the number of tests done. For our primary (age adjusted) analysis shown in tables 1-5, we have made 67 comparisons of specific ethnic groups against the White Scottish reference population. The work followed the prior analysis plan. In $5 \%$ of instances, by chance, we would expect the $95 \%$ CIs not to include 100 -that is, on about $3 / 4$ occasions. The results should be interpreted cautiously given the limits of the methodology, the underlying data and the number of comparisons made. ${ }^{29}$

We did not undertake analysis of statistical interactions, as the risk of misleading inferences is high given the insufficient outcomes for most ethnic groups. Our observations merit corroboration, preferably in larger multiethnic populations.

\section{The findings in the context of the scientific literature}

Ethnic variations in hospitalisation may reflect differing disease incidence, accessibility of both primary and hospital inpatient and outpatient care, and healthcare seeking behaviour. With the exception of appendicitis, most cases will be treated in primary care and in outpatients. Some patients may never go to hospital, and would be missed in our study. Imaging and minor procedures may, however, take place in day case hospitalisation (no overnight stay), which is included in our database. There may be differences by ethnic group in behaviour in relation to the options for healthcare. This possibility could explain some of the ethnic variations we observed. In considering the importance of this, it is noteworthy that in Scotland all healthcare, including prescriptions for drugs, is free at the point of delivery, and that law, 


\begin{tabular}{|c|c|c|c|c|c|c|c|}
\hline Sex and ethnic group & Events (N) & PY at risk & $\begin{array}{l}\text { Rates (per } \\
100000 \text { PY) }\end{array}$ & $\begin{array}{l}\text { Age adjusted } \\
\text { RR and } 95 \% \mathrm{Cl}\end{array}$ & $\begin{array}{l}\text { Age and SIMD } \\
\text { adjusted RR and } \\
95 \% \mathrm{CI}\end{array}$ & $\begin{array}{l}\text { Age and COB } \\
\text { adjusted } \mathrm{RR} \text { and } 95 \% \mathrm{Cl}\end{array}$ & $\begin{array}{l}\text { Age, SIMD and COB } \\
\text { adjusted RR and } \\
95 \% \mathrm{CI}\end{array}$ \\
\hline \multicolumn{8}{|l|}{ Men } \\
\hline White Scottish & 36094 & 11810750 & 305.6 & 100.0 & 100.0 & 100.0 & 100.0 \\
\hline Other White British & 2843 & 1062110 & 382.1 & $125.0(112.8$ to 138.6$)$ & $128.9(115.8$ to 143.5$)$ & $117.0(103.6$ to 132.1$)$ & $122.4(108.2$ to 138.4$)$ \\
\hline White Irish & 564 & 143374 & 537.9 & 176.0 (156.9 to 197.5$)$ & $169.3(150.2$ to 190.8$)$ & 164.1 (143.3 to 187.9$)$ & 160.3 (139.9 to 183.8$)$ \\
\hline Other White & 349 & 175360 & 357.7 & $117.1(104.9$ to 130.6$)$ & $118.4(103.9$ to 134.9$)$ & $119.6(104.8$ to 136.6$)$ & 120.5 (104.8 to 138.4$)$ \\
\hline Any Mixed background & 27 & 17511 & 404.2 & $132.3(96.1$ to 182.0$)$ & $129.5(98.4$ to 170.5$)$ & 128.1 (87.9 to 186.6$)$ & $126.2(93.1$ to 171.1$)$ \\
\hline Indian & 39 & 35291 & 244.3 & $80.0(66.3$ to 96.4$)$ & $83.5(63.4$ to 110.0$)$ & $83.4(67.4$ to 103.2$)$ & $86.3(65.1$ to 114.4$)$ \\
\hline Pakistani & 47 & 64323 & 188.2 & 61.6 (48.3 to 78.5$)$ & 61.5 (48.1 to 78.6$)$ & 64.4 (51.9 to 79.8$)$ & 63.7 (49.6 to 81.7$)$ \\
\hline Other South Asian & 18 & 17620 & 253.5 & 83.0 (55.4 to 124.2$)$ & 83.1 (52.8 to 130.8$)$ & 85.4 (57.9 to 126.0$)$ & 85.0 (52.7 to 137.0$)$ \\
\hline African origin & 19 & 17621 & 302.5 & 99.0 (69.2 to 141.6$)$ & 96.3 (57.9 to 159.9$)$ & 100.7 (61.8 to 163.9$)$ & 97.5 (56.4 to 168.6$)$ \\
\hline Chinese & 21 & 34866 & 144.0 & 47.1 (31.0 to 71.6$)$ & 47.9 (33.2 to 69.2$)$ & 49.3 (32.6 to 74.7$)$ & 49.7 (34.6 to 71.4$)$ \\
\hline \multicolumn{8}{|l|}{ Women } \\
\hline White Scottish & 51904 & 13515409 & 384.0 & 100.0 & 100.0 & 100.0 & 100.0 \\
\hline Other White British & 3656 & 1161246 & 528.1 & 137.5 (123.6 to 153.0$)$ & $142.7(127.5$ to 159.8$)$ & $133.4(117.7$ to 151.1$)$ & $141.1(125.5$ to 158.7$)$ \\
\hline White Irish & 793 & 163506 & 677.1 & 176.3 (161.7 to 192.2$)$ & 167.6 (148.0 to 189.8$)$ & $170.6(152.1$ to 191.3$)$ & 165.6 (145.1 to 188.8$)$ \\
\hline Other White & 499 & 212348 & 492.7 & $128.3(113.1$ to 145.5$)$ & 131.5 (115.6 to 149.5$)$ & $130.2(114.9$ to 147.6$)$ & $132.2(116.4$ to 150.1$)$ \\
\hline Any Mixed background & 42 & 21818 & 555.5 & $144.6(107.4$ to 194.8$)$ & $140.0(108.4$ to 180.8$)$ & $142.6(110.8$ to 183.4$)$ & $139.2(109.7$ to 176.7$)$ \\
\hline Indian & 29 & 31588 & 280.1 & 72.9 (53.3 to 99.9$)$ & 76.3 (53.7 to 108.5$)$ & 74.5 (49.8 to 111.7$)$ & 76.9 (53.6 to 110.4$)$ \\
\hline Pakistani & 34 & 63486 & 208.4 & 54.3 (43.8 to 67.3 ) & 54.0 (40.2 to 72.6$)$ & 55.5 (45.1 to 68.3$)$ & 54.5 (40.2 to 73.8$)$ \\
\hline Other South Asian & 19 & 13984 & 421.8 & 109.8 (85.7 to 140.7$)$ & 108.1 (69.2 to 168.7$)$ & 110.5 (72.4 to 168.5$)$ & $108.3(68.4$ to 171.4$)$ \\
\hline African origin & 22 & 15474 & 458.4 & 119.4 (79.6 to 178.9$)$ & 117.0 (83.7 to 163.6$)$ & 119.6 (79.5 to 179.9$)$ & 117.1 (83.4 to 164.5$)$ \\
\hline Chinese & 21 & 36441 & 176.8 & 46.0 (30.4 to 69.8$)$ & 47.2 (32.4 to 68.7$)$ & 47.2 (27.7 to 80.3$)$ & 47.6 (31.6 to 71.8$)$ \\
\hline
\end{tabular}


strategy and healthcare planning (including free translation services) promote equity in healthcare across ethnic groups. ${ }^{30}$ Studies examining all such possibilities simultaneously are not available.

The literature on ethnic variations in lower GI disorders is limited in the number of studies, the range of study designs (mostly clinical case series ${ }^{9-11} 17$ or crosssectional studies ${ }^{20}{ }^{31}$ ), the range of ethnic groups studied (mostly two or three) and the number of outcomes (mostly one). We are not aware of another cohort design study providing directly comparable data, although there are similar studies from the USA and Scandinavia on ethnic groups different from ours. ${ }^{16} 17$ The US study examined the prevalence, hospitalisation and mortality from inflammatory bowel diseases. Non-Hispanic Whites had more inflammatory bowel disease than non-Hispanic Blacks, who had more than Hispanics.

Our disease rates are higher than those in a standardised study in 20 European centres of incidence of ulcerative colitis and Crohn's disease. ${ }^{7}$ The European study was between 1991 and 1993. The UK centre was in Leicester, where the age range was restricted to 15 upwards, and rates were based on case ascertainment. ${ }^{7}$ There were only 45 cases of ulcerative colitis and 15 cases of Crohn's disease in the UK centre in Leicester. The crude rates/100 000 in men and women combined were 9.2 in non-immigrants and 15.1 in immigrants for ulcerative colitis; 3.2 and 4.7, respectively, for Crohn's disease. These rates were similar to those in all northern centres. ${ }^{7}$ Our higher rates probably reflect different approaches to data collection, the use of all diagnostic codes in hospital and death data, rising rates over time and that Scotland is a high incidence country. While the rates cannot be easily compared to those in the other literature, the RRs can be. Given the differences in ethnic variations by outcome, we discuss each outcome separately.

\section{Irritable bowel syndrome}

Characterised by abdominal pain, bloating and diarrhoea, ${ }^{32}$ IBS is common. ${ }^{17}$ Hospital care may be required as the symptoms mimic more serious disorders. The cause is unknown. The symptoms are mimicked by lactose intolerance, which is most common in non-White populations. ${ }^{33}$

The frequency of IBS varies internationally. ${ }^{1}$ One review concluded that there was no reliable study in the West reporting data by ethnic group. ${ }^{5}$ In a population survey in Singapore, IBS prevalence was similar in the Indian, Malay and Chinese groups, though the prevalence at about 3\% was much lower than reported in the USA and England. ${ }^{20}$ Some reviews have indicated that there are no consistent differences by ethnic group ${ }^{15}$ supporting the work in Singapore. ${ }^{20}$ One systematic review, however, pointed to a lower prevalence of IBS in Eastern countries compared to Western ones, with healthcare seeking being one of the explanations. ${ }^{18}$
Ethnic variations in IBS in SHELS were small as previously observed $^{1}$ with the highest risks in Other White British men and women and the lowest risks in some non-White groups, for example, Pakistani women. These findings go counter to concerns that IBS may be misdiagnosed in populations with a high prevalence of lactose intolerance, that is, non-White groups. ${ }^{33}$ The findings in Other White British people show the potential importance of disaggregating White subgroups. The higher risk in this group is unlikely to relate to genetic factors as genetic composition is very similar to that in the White Scottish group. To study whether the higher risk relates to differences in healthcare utilisation or differences in dietary or other potentially causal factors requires community surveys and primary care consultation data.

\section{Appendicitis}

Appendicitis requires hospital admission, so our data are most likely to reflect disease incidence. ${ }^{1}$ The cause of appendicitis is obscure with major hypotheses relating to dietary fibre ${ }^{2}$ and immune response to infections. ${ }^{3}$ In Scotland, Matheson et $a l^{14}$ observed a rise in hospital discharge rates between 1971 and 1985 in Asian boys 1019 years, but not in those less than 10 years, or in White boys. Their work supported both dietary change and immune regulation hypotheses, but there have been no further studies. (Our age-specific results were not disclosed because of the small numbers of outcomes and the risk of inadvertent disclosure of identity, but the ethnic group variations were similar across the 0-9, 10-19 and all age groups combined.) While ethnic and racial variations in appendicitis have been linked in the USA to access to healthcare, ${ }^{22} 23$ we think it is unlikely that access is related to ethnic variations in Scotland, given its comprehensive NHS. As for diverticular disease, we found higher risks in White males and females and any Mixed background females (but not males) and lower risks in some non-White groups, most clearly so in Indian females and Pakistani males and females. The findings suggest a commonality in causal factors for appendicitis and diverticulitis, as emphasised by Painter and Burkitt. ${ }^{2}$ We think these patterns fit with a dietary hypothesis for both conditions.

\section{Crohn's disease and ulcerative colitis}

As Crohn's disease and ulcerative colitis are characterised by inflammation and ulcers and hospitalisation is often required to manage exacerbations and complications, they are usually considered together. ${ }^{1}$ The causes of both diseases are unknown. For Crohn's disease, one intriguing hypothesis is mycobacterial infection, but the evidence remains equivocal. ${ }^{4}$ Cigarette smoking is protective for ulcerative colitis (a possible effect of nicotine) but harmful for Crohn's disease. ${ }^{4}$ The role of dietary factors is unclear. International variations in racial/ethnic variations have been observed in several countries, with the view that differences are narrowing, thus emphasising the role of local environmental factors. ${ }^{4}$ Both diseases have been rising in 
incidence and are most common in affluent, industrialised societies. Several studies have highlighted the comparatively high risks of inflammatory bowel disease in South Asian populations, but similar risks in African-Caribbean ones, in the UK setting. ${ }^{1} \quad 12 \quad 13 \quad 15$ One study in Leicestershire indicated that compared to White Europeans, South Asians had a high risk of ulcerative colitis, but low risk of Crohn's disease. ${ }^{13}$ A house-to-house survey in Punjab, India in 1999 reported incidence and prevalence rates slightly lower than those in Europe and North America. ${ }^{34}$ A small study in Singapore suggested a higher risk of ulcerative colitis in Indian compared to Chinese and Malays, with no difference in Crohn's disease. $^{19}$

We found that risks were similar across White subgroups (though lower for ulcerative colitis in White Irish men and Other White women). However, for both Crohn's disease and ulcerative colitis, risks were higher in Pakistani men and women. Overall, and unlike other studies, ethnic variations were similar for ulcerative colitis and Crohn's disease, suggesting commonalities in causation. Adjustment for country of birth led to a still higher risk in Pakistani men, suggesting that the risk may be higher in UK-born Pakistani men than in those born outside the UK. This observation needs to be examined in larger populations with sufficient power, which we do not have, for stratified and interaction analyses. A clinical study in London, however, showed no difference in ulcerative colitis in UK-born and foreign-born South Asians. ${ }^{15}$ The European Study (EC-IBD) had data on immigrants and non-immigrants only in Leicester, but the numbers were too small to provide a clear answer. ${ }^{7}$

\section{Diverticular disease}

International variations in diverticular disease, showing high rates in European ${ }^{7}$ and other industrialised countries and low rates in Africa and Asia, have led to the low dietary fibre hypothesis. ${ }^{2}$ If non-White ethnic groups consume more traditional, high fibre diets, we could expect they would have lower risks. There was an exceptionally low rate of disease in Bangladeshis in Tower Hamlets in London, despite the evidence of a high sugar, low fibre diet (and high rates of diabetes and heart disease) leading researchers to question the validity of the fibre hypothesis. ${ }^{11}$

Our results, we think, uniquely show that White Irish, Other White and Other White British people had substantially higher risks compared to White Scottish, though Scotland has long been associated with a very high risk. ${ }^{35}$ We also found high risks for Mixed ethnic group populations (we found no comparable studies). We found lower risk in Indian, Pakistani and Chinese groups, in alignment with previous publications. ${ }^{10} 1117$ Diverticulitis was also rare in Turkish immigrants in the Netherlands ${ }^{36}$ and less common in non-Western immigrants in Sweden, though risks increased after settlement. ${ }^{17}$ In a Malaysian clinic based case series of 410 patients, diverticula were more common in Chinese $(15 \%)$ than Indians $(9 \%)$, but this was not so in our data.
Overview of results and implications for policy, practice and research

The White Scottish reference population, though characterised as having poor health in a European context, and an exceptionally high rate of lower bowel cancer, ${ }^{26}$ tended to be intermediate for the five outcomes studied. The variations in patterns by outcome indicate that these are not simply a result of differential use of healthcare for diagnosis or treatment in hospital (which would affect all outcomes similarly), but do reflect underlying differences in disease incidence. The policy implication is that, at least in Scotland but probably in other multiracial and multiethnic societies too, clinicians and healthcare planners cannot assume similarity of needs for gastroenterology services across ethnic groups.

GI researchers have noted the potential for understanding causation through development and refinement of hypotheses using the ethnic variations model. ${ }^{451014}$ Our analysis on a national scale reaffirms the potential value of this kind of work. In future, we need more case-control and prospective cohort designs with collection of risk factor data. There are also important variations in the frequency of GI cancers that may well have similar underlying reasons. ${ }^{26}{ }^{37} \mathrm{~A}$ multidisciplinary network on ethnic variations in GI disease could provide a foundation for large-scale causal studies as well as providing disease frequency data for policy and clinical service planning.

\section{Author affiliations}

${ }^{1}$ Edinburgh Ethnicity and Health Research Group (EEHRG), Centre for Population Health Sciences, University of Edinburgh, Edinburgh, UK ${ }^{2}$ Cardiovascular Epidemiology Unit, Department of Public Health \& Primary Care, Strangeways Research Laboratory, University of Cambridge, Wort's

Causeway, Cambridge, UK

${ }^{3}$ Public Health and Intelligence, NHS National Services Scotland, Gyle Crescent, Edinburgh, UK

${ }^{4}$ Gastroenterology and Liver Units, University of Birmingham, Queen Elizabeth Hospital, Birmingham, UK

${ }^{5}$ Department of Gastroenterology, Wellington Regional Hospital, Capital and Coast District Health Board, Newtown, Wellington, New Zealand

Acknowledgements Anne Houghton, Arti Nair, Jenny Holmes and Kathryn Ellis gave secretarial help to prepare the paper and to general administration. Judith Fernandez led in preparing the figure.

Collaborators Contributors from the Scottish Health and Ethnicity Linkage Study research team: These contributors served on the Steering Group and some on other important subgroups of SHELS, thus giving general direction that helped this analysis. Colin Fischbacher was a coapplicant with lead responsibility for ISD (Information Services Division) involvement. Chris Povey was a coapplicant and the originator of the idea of linking the census data to the data held by ISD who performed most of the linkage work including developing linkage methods. Prof Jamie Pearce (a coapplicant) advised especially on socioeconomic adjustment. Duncan Buchanan (a coapplicant) chaired the analysis subgroup. Prof Aziz Sheikh was a coapplicant. Markus Steiner was a research fellow providing support in many aspects of SHELS. Ganka Mueller (part study), Alex Stannard (part study) and Kirsty MacLachlan advised particularly in relation to NRS contributions. Anne Douglas coordinated the final phases of this study. These important contributions did not meet the ICMJE authorship requirements.

Contributors The authorship, the authorship byline, and note of contributions follow SHELS policy on authorship. All authors served on the Gl subgroup of SHELS which planned the work in detail. RSB was the chief investigator of 
SHELS and lead writer of this paper, GC was the researcher and primary analyst, NB was the research fellow and coordinator of the study, HJTW was a collaborator, and NB was the chair of the GI subgroup. All authors helped conceptualise and plan the study, evolve analysis plans, interpret data and critically revise drafts of the manuscript.

Funding The authors thank the Chief Scientist Office for a grant $(\mathrm{CZH} / 4 / 648)$, NHS Health Scotland for a supplementary grant and the Equality and Diversity Information Programme of the Information Services Division (ISD) of NHS National Services Scotland for support. ISD and the General Register Office for Scotland both made 'in-house' contributions to the work.

Competing interests None.

Disclaimer The researchers acted independently of the funding body and the study sponsor (the University of Edinburgh) at all stages of the work.

Ethics approval The Multicentre Research Ethics Committee for Scotland and the Privacy Advisory Committee of NHS National Services Scotland gave approvals.

Provenance and peer review Not commissioned; externally peer reviewed.

Data sharing statement The data are not open access. They are only available in a data safe haven with restricted access at National Records Scotland, and governed by strict ethical and other restrictions on access. Individual consent for linking these records was not sought. Researchers wishing to utilise the data should write to Professor Raj Bhopal with a brief proposal, which will be examined by the SHELS Executive Group.

Open Access This is an Open Access article distributed in accordance with the Creative Commons Attribution Non Commercial (CC BY-NC 4.0) license, which permits others to distribute, remix, adapt, build upon this work noncommercially, and license their derivative works on different terms, provided the original work is properly cited and the use is non-commercial. See: http:// creativecommons.org/licenses/by-nc/4.0/

\section{REFERENCES}

1. Williams JG, Roberts SE, Ali MF, et al. Gastroenterology services in the UK. The burden of disease, and the organisation and delivery of services for gastrointestinal and liver disorders: a review of the evidence. Gut 2007;56(Suppl 1):1-113.

2. Painter NS, Burkitt DP. Diverticular disease of the colon: a deficiency disease of Western civilization. Br Med J 1971;2:450-4.

3. Barker DJ. Acute appendicitis and dietary fibre: an alternative hypothesis. Br Med J (Clin Res Ed) 1985;290:1125-7.

4. Loftus Jr EV. Clinical epidemiology of inflammatory bowel disease: incidence, prevalence, and environmental influences. Gastroenterology 2004;126:1504-17.

5. Kang JY. Systematic review: the influence of geography and ethnicity in irritable bowel syndrome. Aliment Pharmacol Ther 2005;21:663-76.

6. Goh KL. Changing trends in gastrointestinal disease in the Asia -Pacific region. J Dig Dis 2007;8:179-85.

7. Shivananda S, Lennard-Jones J, Logan $\mathrm{R}$, et al. Incidence of inflammatory bowel disease across Europe: is there a difference between north and south? Results of the European Collaborative Study on Inflammatory Bowel Disease (EC-IBD). Gut 1996;39:690-7.

8. Bhopal RS. Migration, ethnicity, race and health in multicultural societies. 2nd edn. Oxford: Oxford University Press, 2014.

9. Goodhand JR, Kamperidis N, Joshi NM, et al. The phenotype and course of inflammatory bowel disease in UK patients of Bangladesh descent. Aliment Pharmacol Ther 2012;35:929-40.

10. Kang JY, Dhar A, Pollok R, et al. Diverticular disease of the colon: ethnic differences in frequency. Aliment Pharmacol Ther 2004;19:765-9

11. Lahiri RP, Abeles A, Burnand KM, et al. A cross sectional study of colonic diverticulosis in the London Bangladeshi population. United Eur Gastroenterol J 2013;1:191-7.

12. Johnson MW, Lithgo K, Price T. The Effect of Ethnicity on the Prevalence of Inflammatory Bowel Disease with the Luton and Dunstable Catchment Region, in UK. Gut 2013;62(Suppl 1):A169-70.
13. Probert CS, Jayanthi V, Hughes AO, et al. Prevalence and family risk of ulcerative colitis and Crohn's disease: an epidemiological study among Europeans and south Asians in Leicestershire. Gut 1993;34:1547-51.

14. Matheson LM, Henderson JB, Hole D, et al. Changes in the incidence of acute appendicitis in Glasgow Asian and white children between 1971 and 1985. J Epidemiol Community Health 1988;42:290-3.

15. Walker DG, Williams HRT, Kane SP, et al. Differences in inflammatory bowel disease phenotype between South Asians and Northern Europeans living in North West London, UK. Am J Gastroenterol 2011;106:1281-9.

16. Nguyen GC, Chong CA, Chong RY. National estimates of the burden of inflammatory bowel disease among racial and ethnic groups in the United States. J Crohns Colitis 2014;8:288-9.

17. Hjern F, Johansson C, Mellgren A, et al. Diverticular disease and migration-the influence of acculturation to a Western lifestyle on diverticular disease. Aliment Pharmacol Ther 2006;23:797-805.

18. Adeyemo MA, Spiegel BM, Chang L, et al. Meta-analysis: do irritable bowel syndrome symptoms vary between men and women? Aliment Pharmacol Ther 2010;32:738-55.

19. Lee YM, Fock K, See SJ, et al. Racial differences in the prevalence of ulcerative colitis and Crohn's disease in Singapore. $J$ Gastroenterol Hepatol 2000;15:622-5.

20. Ho KY, Kang JY, Seow A. Prevalence of gastrointestinal symptoms in a multiracial Asian population, with particular reference to reflux-type symptoms. Am J Gastroenterol 1998;93:1816-22.

21. Basu D, Lopez I, Kulkarni A, et al. Impact of race and ethnicity on inflammatory bowel disease. Am J Gastroenterol 2005;100:2254-61.

22. Gerst PH, Mukherjee A, Kumar A, et al. Acute appendicitis in minority communities: an epidemiologic study. J Natl Med Assoc 1997;89:168-72.

23. Lawrence VA, Tuley MR, Diehl AK, et al. Appendicitis: higher risk in Mexican Americans? Ethn Health 1996;1:237-43.

24. Gill PS, Kai J, Bhopal RS, et al. Health care needs assessment: black and minority ethnic groups. In: Raftery J, ed. Health care needs assessment. The epidemiologically based needs assessment reviews. Third Series edn. Abingdon: Radcliffe Medical Press Ltd, 2007:227-389.

25. Bhopal R, Fischbacher C, Povey C, et al. Cohort profile: Scottish Health and Ethnicity Linkage Study of 4.65 million people exploring ethnic variations in disease in Scotland. Int $J$ Epidemiol 2011;40:1168-75

26. Bhopal R, Bansal N, Steiner M, et al on behalf of the Scottish Health and Ethnicity Linkage Study. Does the 'Scottish effect' apply to all ethnic groups? All cancer, lung, colorectal, breast and prostate cancer in the Scottish Health and Ethnicity Linkage Cohort Study. BMJ Open 2012;2:e001957.

27. Fischbacher CM, Cezard G, Bhopal RS, et al. Measures of socioeconomic position are not consistently associated with ethnic differences in cardiovascular disease in Scotland: methods from the Scottish Health and Ethnicity Linkage Study (SHELS). Int $J$ Epidemiol 2014:43:129-39.

28. Boyd KM. Ethnicity and the ethics of data linkage. BMC Public Health 2007;7:318.

29. Rothman KJ, Greenland S. Modern epidemiology. Lippincott-Raven, 1998.

30. Bhopal RS. The quest for culturally sensitive health-care systems in Scotland: insights for a multi-ethnic Europe. J Public Health 2012;34:5-11.

31. Peery AF, Barrett PR, Park D, et al. A high-fiber diet does not protect against asymptomatic diverticulosis. Gastroenterology 2012;142:266-72.

32. Ford AC, Talley NJ. Irritable bowel syndrome. BMJ 2012;345:e5836.

33. Matthews SB, Waud JP, Roberts AG, et al. Systemic lactose intolerance: a new perspective on an old problem. Postgrad Med $J$ 2005:81:167-73.

34. Sood A, Midha V, Sood N, et al. Incidence and prevalence of ulcerative colitis in Punjab, North India. Gut 2003;52:1587-90.

35. Kyle J, Adesola AO, Tinckler LF, et al. Incidence of diverticulitis. Scand J Gastroenterol 1967;2:77-80.

36. Loffeld RJ. Diverticulosis of the colon is rare amongst immigrants living in the Zaanstreek region in the Netherlands. Colorectal Dis 2005;7:559-62.

37. Ali R, Barnes I, Cairns BJ, et al. Incidence of gastrointestinal cancers by ethnic group in England, 2001-2007. Gut 2013;62:1692-703. 